\title{
Synthesis of Nanocobalt Powders for an Anode Material of Lithium-Ion Batteries by Chemical Reduction and Carbon Coating
}

\author{
Seong-Hyeon Hong, ${ }^{1}$ Yeong-Mi Jin, ${ }^{2}$ Kyung Tae Kim, ${ }^{1}$ Cheol-Woo Ahn, \\ Dong-Su Park, ${ }^{3}$ and Myoung Youp Song ${ }^{4}$ \\ ${ }^{1}$ Powder Technology Group, Korea Institute of Materials and Science (KIMS), Affiliated with Korea Institute of Machinery and \\ Materials, 797 Changwon-daero, Seongsan-gu, Changwon, Gyeongsangnam-do 642-831, Republic of Korea \\ ${ }^{2}$ Hwa Sung Thermo Co., Ltd., 40 Sandan-ro, 197 Beon-gil, Pyeongtaek-si, Gyeonggi-do 459-050, Republic of Korea \\ ${ }^{3}$ Functional Ceramics Group, Korea Institute of Materials and Science (KIMS), Affiliated with Korea Institute of Machinery and \\ Materials, 797 Changwon-daero, Seongsan-gu, Changwon, Gyeongsangnam-do 642-831, Republic of Korea \\ ${ }^{4}$ Division of Advanced Materials Engineering, Research Center of Advanced Materials Development, Engineering Research Institute, \\ Chonbuk National University, 567 Baekje-daero, Deokjin-gu, Jeonju 561-756, Republic of Korea
}

Correspondence should be addressed to Myoung Youp Song; songmy@jbnu.ac.kr

Received 25 October 2013; Revised 30 March 2014; Accepted 1 April 2014; Published 19 May 2014

Academic Editor: Necdet Aslan

Copyright (C) 2014 Seong-Hyeon Hong et al. This is an open access article distributed under the Creative Commons Attribution License, which permits unrestricted use, distribution, and reproduction in any medium, provided the original work is properly cited.

\begin{abstract}
Nanosized Co powders were prepared by a chemical reduction method with and without CTAB (cetyltrimethylammonium bromide, $\mathrm{C}_{19} \mathrm{H}_{42} \mathrm{BrN}$ ) and carbon-coating heat treatment at $700^{\circ} \mathrm{C}$ for $1 \mathrm{~h}$, and the electrochemical properties of the prepared nanosized Co powders were examined to evaluate their suitability as an anode material of Li-ion batteries. Nanosized amorphous Co-based powders could be synthesized by a chemical reduction method in which a reducing agent is added to a Co ion-dissolved aqueous solution. When the prepared nanosized Co-based powders were subjected to carbon-coating heat treatment at $700^{\circ} \mathrm{C}$ for $1 \mathrm{~h}$, the amorphous phase was crystallized, and a Co single phase could be obtained. The Co-based powder prepared by chemical reduction with CTAB and carbon-coating heat treatment had a smaller first discharge capacity (about $557 \mathrm{mAh} / \mathrm{g}$ ) than the Cobased powder prepared by chemical reduction without CTAB and carbon-coating heat treatment (about $628 \mathrm{mAh} / \mathrm{g}$ ). However, the former had a better cycling performance than the latter from the third cycle. The carbon-coated layers are believed to have led to quite good cycling performances of the prepared Co-based powders from the third cycle.
\end{abstract}

\section{Introduction}

There is much interest in several different types of lithiumbased rechargeable batteries [1-9], due to the expectation of high specific energies and energy densities. The conventional lithium-ion batteries use carbon-based materials as anodes [10-12], but their theoretical capacity of $372 \mathrm{mAh} / \mathrm{g}$ is not sufficient. Therefore, the development of new anode materials with high capacity is needed.

Much work has been conducted on the subject of electrodes using nanosized materials since nanosized powders exhibit good electrochemical performance. Nanosized powder can be synthesized by various methods, such as sol-gel
[13], solvothermal [14], spray conversion [15], and pulsed wire evaporation (PWE) methods [16].

Kim et al. [17] synthesized nanosized Co powder by a pulsed wire evaporation method as an anode material for lithium batteries. The Li/Co cell fabricated with the powder showed a plateau potential of $0.7 \mathrm{~V}$ and a capacity of $440 \mathrm{mAh} / \mathrm{g}$ at the first discharge, and a reversible capacity of about $280 \mathrm{mAh} / \mathrm{g}$ after 30 cycles.

An ordered mesoporous Sn-C composite with Sn nanoparticles confined in carbon nanorods was prepared by Chen et al. [18]. This composite delivered a reversible lithium storage capacity of $554 \mathrm{mAh} / \mathrm{g}$ at the 200th cycle as an anode material of Li-ion batteries. 
Cobalt composites are potential candidates for use as an anode material. Examples are Co-O [19], Co-C [20, 21], Co$\mathrm{Sb}[22], \mathrm{Co}-\mathrm{Sn}[23,24]$, and Co-B [25] composites.

Yue et al. [21] synthesized a novel C/Co composite with Co nanoparticles embedded in carbon matrix by the pyrolysis of polymeric cobalt phthalocyanine (PcCo) at $700^{\circ} \mathrm{C}$ in argon atmosphere. They reported that the $\mathrm{C} / \mathrm{Co}$ electrode had a reversible capacity of over $600 \mathrm{mAh} / \mathrm{g}$ at a current of $50 \mathrm{mAh} / \mathrm{g}$ after 40 cycles and showed better rate capability and less hysteresis in comparison with carbon not containing Co.

He et al. [24] performed hydrothermal synthesis and examined the electrochemical properties of nanosized CoSn alloy anodes for lithium-ion batteries. They reported that prolonging the dwelling time at the same hydrothermal temperature could increase the content of Sn oxides, which would lead to a high initial irreversible capacity loss, but better cycling stability, owing to the buffer effect of the irreversible product $\mathrm{Li}_{2} \mathrm{O}$.

Yiping et al. [25] produced Co-B fine particles by the chemical reduction of aqueous solutions of cobalt chloride with sodium borohydride. The particle size was in the range of 20-100 nm. Ultrafine $\mathrm{Co}_{74.4} \mathrm{~B}_{25.6}$ amorphous powder was prepared by Yuan et al. [26] with chemical reduction. The as-prepared sample was formed by many interconnected fine particles with sizes smaller than $100 \mathrm{~nm}$.

Co-based powders were prepared via the chemical reduction method by several researchers. Lu et al. [27] reduced cobalt (II) by chemical reduction. They added sodium borohydride at a controlled rate, with the concentration of $\mathrm{NaOH}$ varied in the reducing solution. The synthesized particle size was about $20-100 \mathrm{~nm}$.

Ahn [28] reported that nanosized anode materials had high discharge capacities but showed poor cycling performances. Carbon coating is thought to improve cycling performances of anode materials by preventing the formation of SEI (solid electrolyte interphase) layers between anode materials and electrolyte.

In this study, nanosized Co powders were prepared by a chemical reduction method with and without CTAB (cetyltrimethylammonium bromide, $\mathrm{C}_{19} \mathrm{H}_{42} \mathrm{BrN}$ ) and carboncoating heat treatment at $700^{\circ} \mathrm{C}$. Then, the electrochemical properties of the prepared nanosized Co powders were examined to evaluate their suitability as an anode material for Li-ion batteries.

\section{Experimental Details}

In order to synthesize nanosized Co-based powders, the materials listed in Table 1 were used.

Figure 1 shows a schematic of the apparatus used for chemical reduction. CTAB is a cationic surfactant (surface active agent) and was added since its addition was expected to facilitate pore formation. CTAB-added Co powders were synthesized as follows. $5.94 \mathrm{~g}$ of cobalt (II) chloride hexahydrate $\left(\mathrm{CoCl}_{2} \cdot 6 \mathrm{H}_{2} \mathrm{O}\right)$ and $2.28 \mathrm{~g}$ of CTAB were dissolved by stirring in $250 \mathrm{cc}$ of distilled water, which was purged sufficiently with high-purity nitrogen. $9.46 \mathrm{~g}$ of a reducing agent granular sodium borohydride was also dissolved by stirring in $250 \mathrm{cc}$

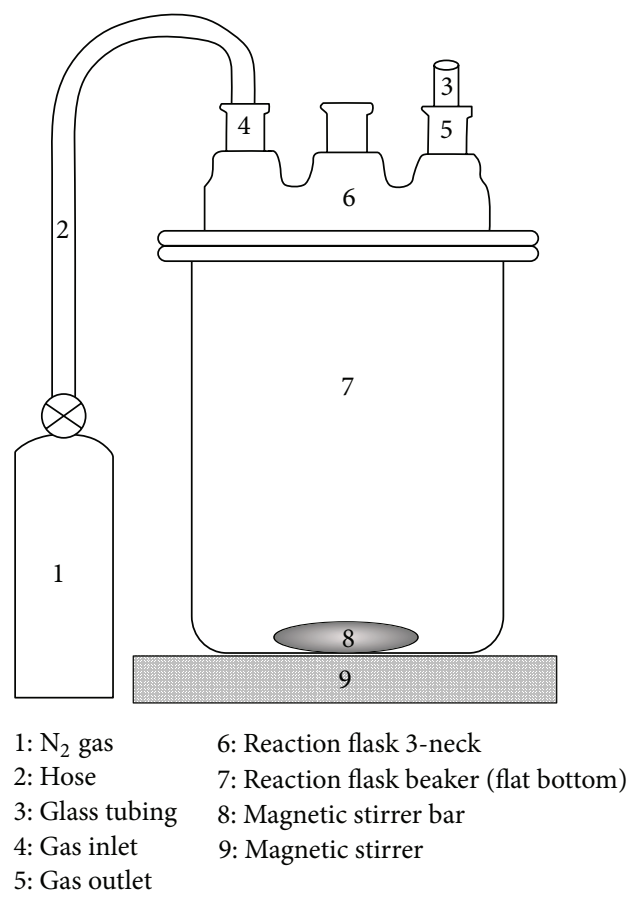

FIGURE 1: Schematic of an apparatus for chemical reduction.

of distilled water, which was also purged sufficiently with high-purity nitrogen. Then, the reducing agent solution was added slowly to the solution containing the solutes in order to prevent abrupt reaction due to CTAB, which can cause boiling over. During this process, nitrogen was purged continuously. After the reaction was completed, the solution was filtered and washed by distilled water and ethanol to prevent oxidation. The prepared powder was then dried.

Co powders without CTAB addition were synthesized as follows. $11.88 \mathrm{~g}$ of cobalt (II) chloride hexahydrate $\left(\mathrm{CoCl}_{2} \cdot 6 \mathrm{H}_{2} \mathrm{O}\right)$ and $18.92 \mathrm{~g}$ of granular sodium borohydride reducing agent were dissolved separately by stirring in $500 \mathrm{cc}$ of distilled water, which was purged sufficiently with highpurity nitrogen. Then, the reducing agent solution was added to the solute-containing solution at a rate of about $500 \mathrm{cc} / \mathrm{min}$. During this process, nitrogen was purged continuously. After the reaction was completed, the solution was filtered and washed by distilled water and ethanol to prevent oxidation, and the prepared powder was dried.

TGA (thermogravimetric analysis) with an SDT2960 (TA Instruments, USA) and DTA (differential thermal analysis) with an STA409pc (Netzsch, Germany) were performed for the synthesized samples by increasing the temperature to $1000^{\circ} \mathrm{C}$ at a heating rate of $10^{\circ} \mathrm{C} / \mathrm{min}$ in an $\mathrm{Ar}$ atmosphere. The sensitivity of the balance was $0.1 \mu \mathrm{g}$.

Then the powder synthesized by the chemical reduction method was carbon-coated in a tune furnace as follows. The powder used as the carbon-coating agent was glucose $\left(\mathrm{C}_{6} \mathrm{H}_{12} \mathrm{O}_{6}\right.$, Oriental Chemical Industries, extra pure). The reaction for carbon coating on the particles prepared by chemical reduction is given by

$$
\mathrm{C}_{6} \mathrm{H}_{12} \mathrm{O}_{6} \longrightarrow 6 \mathrm{C}+6 \mathrm{H}_{2} \mathrm{O}
$$


TABLE 1: Raw materials used in this work.

\begin{tabular}{lccc}
\hline Material & Molecular formula & Purity & Manufacturing company \\
\hline Cobalt (II) chloride hexahydrate & $\mathrm{CoCl}_{2} \cdot 6 \mathrm{H}_{2} \mathrm{O}$ & $97.0 \%$ & Samchun Pure Chemical Co., Ltd. \\
Sodium borohydride & $\mathrm{NaBH}_{4}$ & $98.0 \%$ & Samchun Pure Chemical Co., Ltd. \\
CTAB (cetyltrimethylammonium bromide) & $\mathrm{C}_{19} \mathrm{H}_{42} \mathrm{BrN}$ & $99.0 \%$ & Samchun Pure Chemical Co., Ltd. \\
\hline
\end{tabular}

When $\mathrm{C}_{6} \mathrm{H}_{12} \mathrm{O}_{6}$ is decomposed, the decrease in weight is $60 \%$, and $40 \%$ remains as carbon. The weight of the glucose was determined by planning the Co-based powder containing $20 \mathrm{wt} \%$ coated carbon after $\mathrm{C}_{6} \mathrm{H}_{12} \mathrm{O}_{6}$ decomposed to carbon on the Co-based powder. The mixed weight ratio of the Co-based powder to the $\mathrm{C}_{6} \mathrm{H}_{12} \mathrm{O}_{6}$ powder was 61.54 :38.46. A determined weight of the $\mathrm{C}_{6} \mathrm{H}_{12} \mathrm{O}_{6}$ powder was dissolved in distilled water with a spoon until precipitates were not observed and then mixed with the dried Co powder. The particles were then dispersed by an ultrasonic cleaner and dried. This dried powder was heat-treated at $700^{\circ} \mathrm{C}$ for $1 \mathrm{~h}$ in Ar atmosphere.

The BET surface areas of the synthesized powders were measured by a BET surface characterizing analyzer (ASAP2010 and TriStar 3000 (Micromeritics, USA)).

The microstructures of the prepared samples were observed by FE-SEM (field emission scanning electron microscope, JXA-8600).

Co-based powder anodes were fabricated by dispersing the powders, carbon (10 wt $\%$ or $20 \mathrm{wt} \%$ ), and polyvinylidene fluoride (PVDF) binder (10 wt\%) in N-methyl-2-pyrrolidone (NMP) to form a slurry, which was spread onto copper foil. After drying the coated slurry at $80^{\circ} \mathrm{C}$ for $12 \mathrm{~h}$ in vacuum, the copper foil coated with the slurry was rolled under a pressure of $100 \mathrm{kgf} / \mathrm{cm}^{2}$. The coated electrode was punched with a $\Phi 14.6 \mathrm{~mm}$ punch. Li/Co-based powder coin cells (type 2016) were then assembled. Li foil metal was used as the counter and reference electrodes. The electrolyte was $1 \mathrm{M} \mathrm{LiPF}_{6}$ in a $1: 1$ (volume ratio) mixture of ethylene carbonate (EC) and diethyl carbonate (DEC). The charge-discharge tests and CV (cyclic voltammetry) tests were performed with a chargedischarge tester (WBCS3000, WonATech Ltd.). The cells were charged and discharged at a current density of $0.2 \mathrm{~mA} / \mathrm{cm}^{2}$ in a voltage range of $0.001 \mathrm{~V}-2.5 \mathrm{~V}$ versus $\mathrm{Li} / \mathrm{Li}^{+}$.

\section{Results and Discussion}

The XRD patterns of the Co-based powders prepared by chemical reduction method with and without CTAB are shown in Figure 2. The prepared powders are amorphous without crystalline peaks in their X-ray diffraction patterns.

Figure 3 presents the FE-SEM (field emission scanning electron microscope) micrographs of Co-based powders prepared by chemical reduction method, (a)-(c) with CTAB and (d)-(f) without CTAB. The particles were dispersed by an ultrasonic cleaner and dried to observe the microstructure by FE-SEM. The effect of the decrease in grain size can be obtained by the chemical reduction method, since the solute in the solution instantly reacts with the reducing agent. This can be seen clearly in Figure 3. The grain size in the sample prepared with $\mathrm{CTAB}$ has a wide particle size distribution

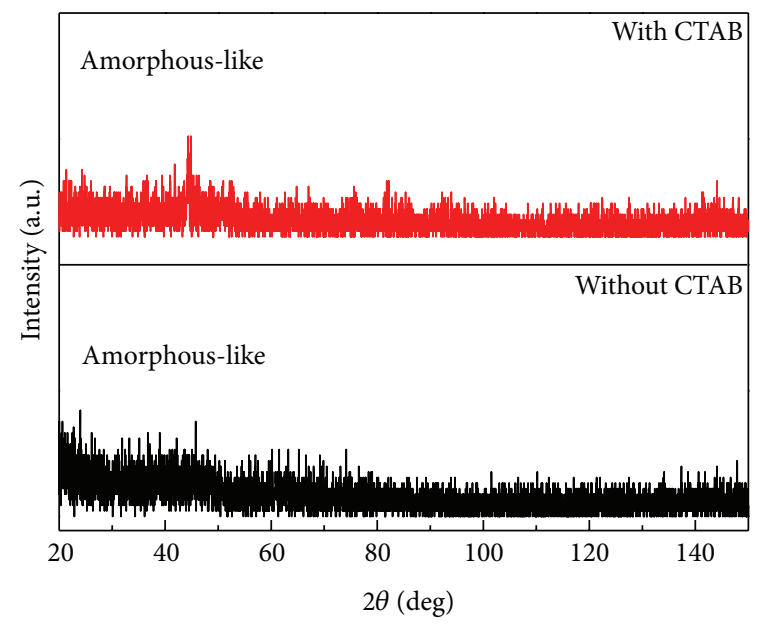

FIGURE 2: XRD patterns of the Co-based powders prepared by chemical reduction with CTAB and without CTAB.

between about $100 \mathrm{~nm}$ and $10-20 \mathrm{~nm}$. The grain size in the sample prepared without CTAB is quite homogeneous with a grain size of about $20 \mathrm{~nm}$. In the sample prepared without $\mathrm{CTAB}$, the fine grains are agglomerated, which can be seen distinctly in the micrographs at high magnifications.

The TGA-DTA results of Co-based powders prepared by chemical reduction method (a) with CTAB and (b) without CTAB are shown in Figure 4. Just after the chemical reduction and drying, the Co-based powders were used for these measurements, in which the temperature was increased to $1,000^{\circ} \mathrm{C}$ at a heating rate of $10^{\circ} \mathrm{C} / \mathrm{min}$ in an $\mathrm{Ar}$ atmosphere. The absorption peak at $139.86^{\circ} \mathrm{C}$ in Figure $4(\mathrm{a})$ does not appear in Figure 4(b). This absorption peak is believed to result from the decomposition of CTAB. The weight decreases rapidly at the beginning $\left(<200^{\circ} \mathrm{C}\right)$ in Figures $4(\mathrm{a})$ and $4(\mathrm{~b})$. This is believed to be due to the evaporation of the distilled water, ethanol, and water vapor adsorbed during storage. The distilled water and ethanol are those which had not been removed during the chemical reduction. The crystallization of Co is expected to occur at about $656.78-730.50^{\circ} \mathrm{C}$. This can be verified in the XRD results obtained after heat treatment at $700^{\circ} \mathrm{C}$.

Figure 5 shows the XRD patterns of Co-based powders prepared by chemical reduction with and without CTAB and carbon-coating heat treatment at $700^{\circ} \mathrm{C}$ for $1 \mathrm{~h}$. Clear peaks corresponding to Co grains appear. Using the Scherrer formula for the main Co peaks, the grain size of the particles prepared with $\mathrm{CTAB}$ and carbon-coated was calculated as $33 \mathrm{~nm}$, which was larger than that of $25 \mathrm{~nm}$ obtained for the particles prepared without CTAB and carbon-coated. The XRD patterns of Co-based powders prepared by chemical 


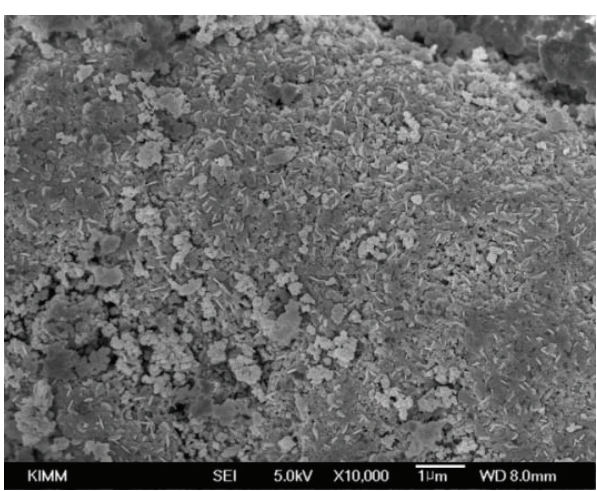

(a)

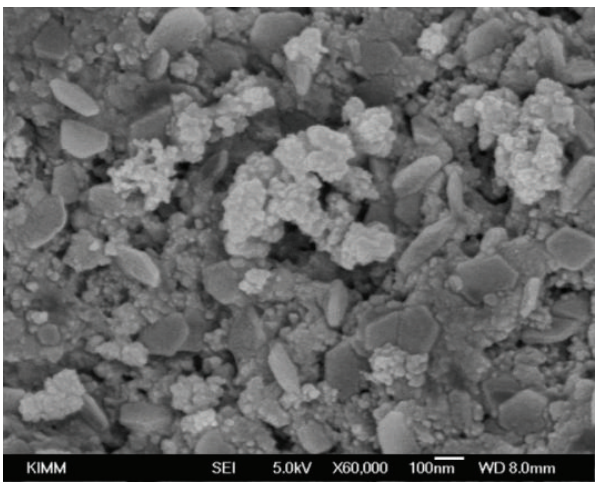

(c)

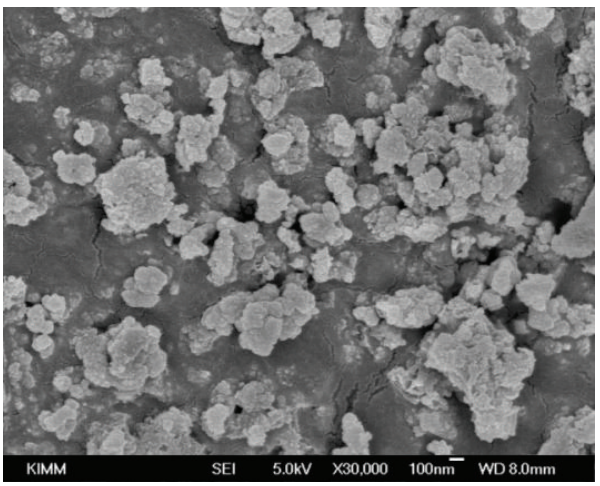

(e)

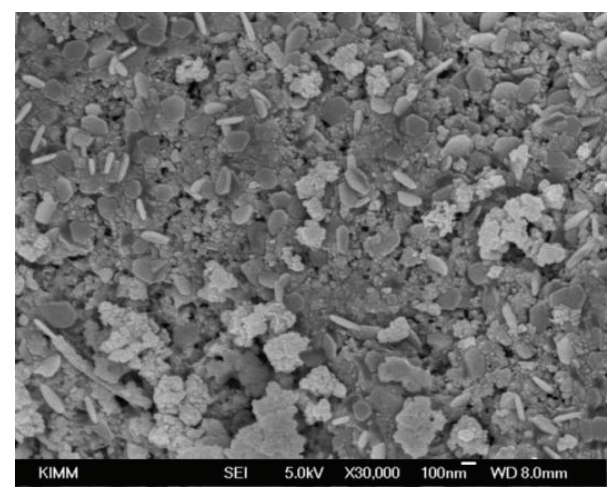

(b)

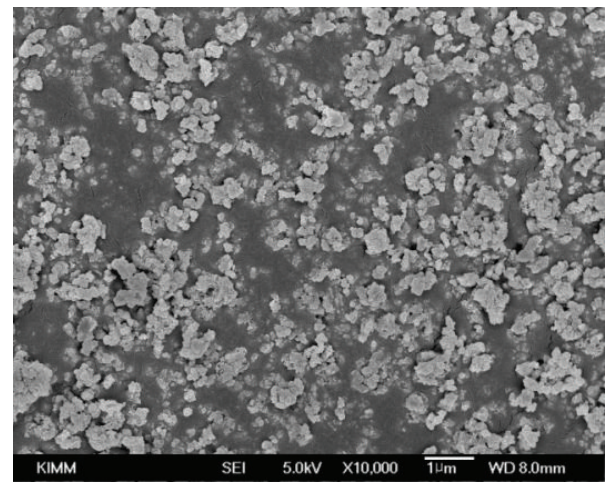

(d)

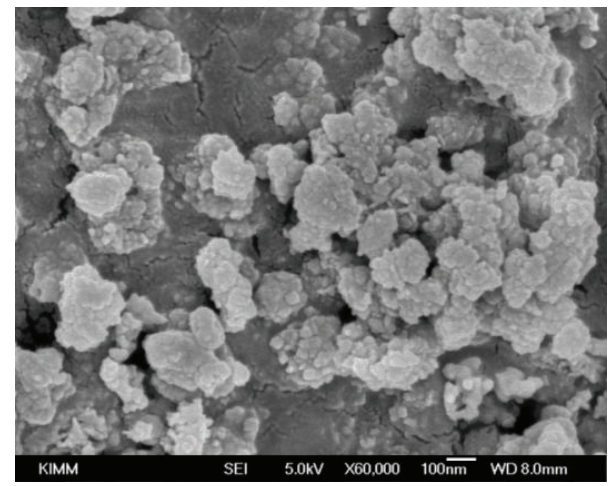

(f)

FIGURE 3: FE-SEM micrographs of the Co-based powders prepared by chemical reduction (a)-(c) with CTAB and (d)-(f) without CTAB.

reduction with and without $\mathrm{CTAB}$ and carbon-coating heat treatment at $500^{\circ} \mathrm{C}$ showed that these Co-based powders were not crystallized, as they were just after chemical reduction.

According to Saida et al. [29], the reaction mechanism of Co powder by chemical reduction is as follows:

$$
\begin{aligned}
& 4 \mathrm{Co}_{2}{ }^{+}+\mathrm{BH}_{4}{ }^{-}+8 \mathrm{OH}^{-} \longrightarrow 4 \mathrm{Co}+\mathrm{BO}_{2}{ }^{-}+6 \mathrm{H}_{2} \mathrm{O} \\
& 4 \mathrm{Co}_{2}{ }^{+}+2 \mathrm{BH}_{4}{ }^{-}+6 \mathrm{OH}^{-} \longrightarrow 2 \mathrm{Co}_{2} \mathrm{~B}+6 \mathrm{H}_{2} \mathrm{O}+\mathrm{H}_{2}
\end{aligned}
$$

These reactions equations show that the reaction between $\mathrm{BH}_{4}{ }^{-}$and Co produces Co or $\mathrm{Co}_{2} \mathrm{~B}$. The formation of $\mathrm{Co}$ in this work suggests that reaction (2) occurs, forming $\mathrm{BO}_{2}{ }^{-}$and $\mathrm{H}_{2} \mathrm{O}$.
The FE-SEM micrographs of Co-based powders prepared by chemical reduction $(a, b)$ with CTAB and $(c, d)$ without $\mathrm{CTAB}$ and carbon-coating heat treatment at $700^{\circ} \mathrm{C}$ for $1 \mathrm{~h}$ are shown in Figure 6. The particles prepared with CTAB and carbon-coated are larger than those prepared without CTAB and carbon-coated. The particles are believed to have increased in size due to the formation of carbon-coated layers. The particles prepared without CTAB and carbon-coated are spherical, while those prepared with CTAB and carboncoated have square shapes with edges.

CTAB was added because we expected its addition to facilitate pore formation. The Co-based powder prepared by chemical reduction without $\mathrm{CTAB}$ and carbon-coating heat treatment at $500^{\circ} \mathrm{C}$ for $1 \mathrm{~h}$ had a BET surface area of 


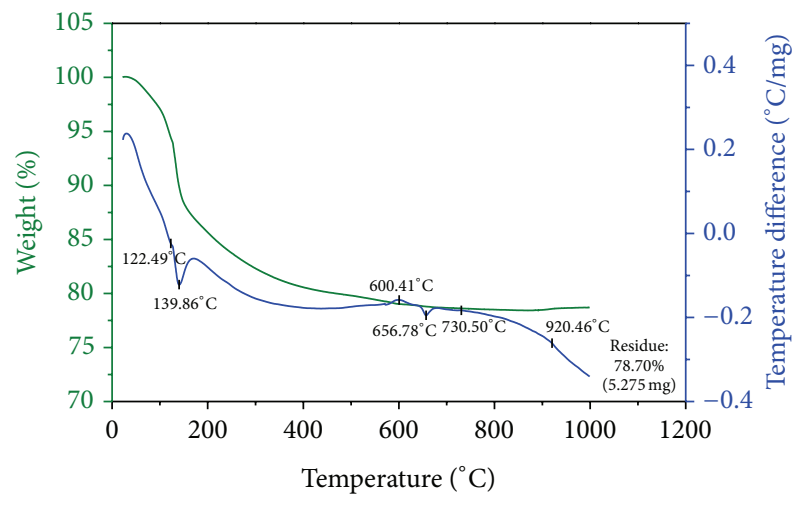

(a)

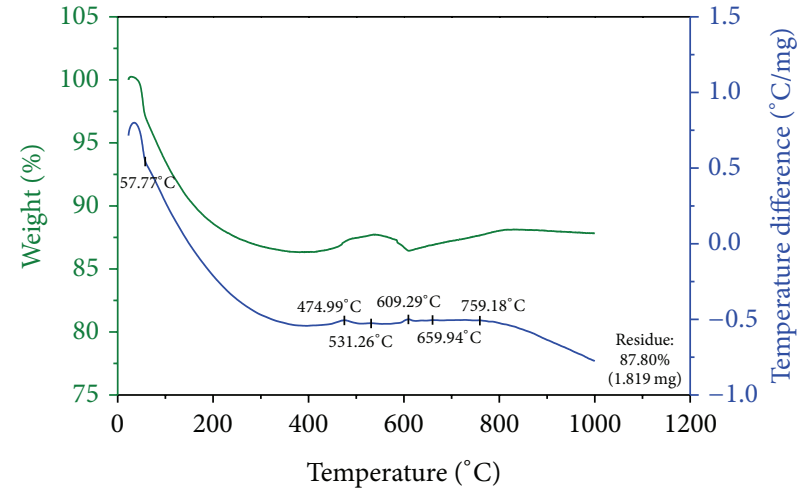

(b)

FIGURE 4: TGA-DTA of the Co-based powders prepared by chemical reduction (a) with CTAB and (b) without CTAB.

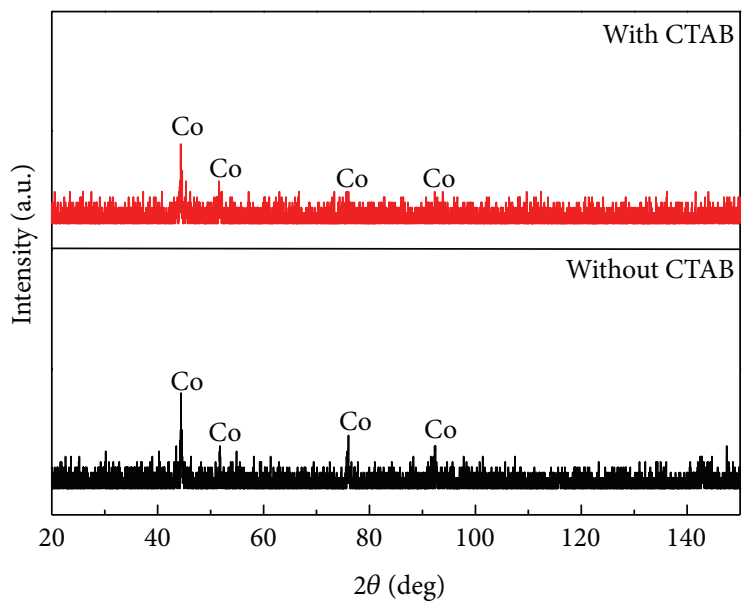

FIGURE 5: XRD patterns of the carbon-coated Co-based powders prepared by chemical reduction with and without CTAB and carbon-coating heat treatment at $700^{\circ} \mathrm{C}$ for $1 \mathrm{~h}$.

$3.80 \mathrm{~m}^{2} / \mathrm{g}$, indicating a high specific area of the powder. The size of these Co-based particles was calculated as $180 \mathrm{~nm}$ from the equation, particle size $=6 /($ specific surface area $\times$ density), by assuming the particles are spherical. The BET surface area of the Co-based powder prepared by chemical reduction with $\mathrm{CTAB}$ and carbon-coating heat treatment at $500^{\circ} \mathrm{C}$ for $1 \mathrm{~h}$ could not be measured due to the difficulty in the maintenance of vacuum. So, it was hard to verify that the addition of CTAB facilitates pore formation.

Figure 7 shows the discharge capacity versus cycle number of Co-based electrodes prepared by chemical reduction with and without $\mathrm{CTAB}$ and carbon-coating heat treatment at $700^{\circ} \mathrm{C}$ for $1 \mathrm{~h}$. The Co-based powder prepared with CTAB and carbon-coated has a smaller first discharge capacity (about $557 \mathrm{mAh} / \mathrm{g}$ ) than the Co-based powder prepared without CTAB and carbon-coated (about $628 \mathrm{mAh} / \mathrm{g}$ ). A decrease in particle size of the host material is believed to be able to buffer the volume expansion involved during charge and discharge. Even though the volume expansion was minimized by preparing nanosized particles, at the beginning of cycling, the discharge capacity decreases quite abruptly. This is believed to be due to the formation of an SEI (solid electrolyte interphase), which obstructs the movements of $\mathrm{Li}$ ions and electrons. However, from the third cycle, the two samples exhibit quite good cycling performances, and the Co-based powder prepared with CTAB and carbon-coated has a better cycling performance than the Co-based powder prepared without CTAB and carbon-coated. The reason why these two samples exhibit quite good cycling performance from the third cycle is believed to be due to the carbon-coated layer which prevents the formation of SEI (solid electrolyte interphase) layers between anode materials and electrolyte.

Poizot et al. [30] reported that electrodes made of nanoparticles of transition-metal oxides ( $\mathrm{MO}$, where $\mathrm{M}$ is $\mathrm{Co}, \mathrm{Ni}, \mathrm{Cu}$, or $\mathrm{Fe}$ ) demonstrated electrochemical capacities of $700 \mathrm{mAh} / \mathrm{g}$, with $100 \%$ capacity retention for up to 100 cycles and high recharging rates. Carbon-coated silicon anodes were reported by Dimov et al. [31] to have a charge capacity of $1,080 \mathrm{mAh} / \mathrm{g}$ at the first cycle and a charge capacity of $1,270 \mathrm{mAh} / \mathrm{g}$ at the second cycle, at the current density of $1 \mathrm{~mA} / \mathrm{cm}^{2}$. Yue et al. [21] reported that the $\mathrm{C} / \mathrm{Co}$ electrode, in which Co nanoparticles are embedded in carbon matrix, had a reversible capacity of over $600 \mathrm{mAh} / \mathrm{g}$ at a current of $50 \mathrm{mAh} / \mathrm{g}$ after 40 cycles. Kim et al. [17] reported that the $\mathrm{Li} / \mathrm{Co}$ cell, fabricated with the nanosized Co powder synthesized by a pulsed wire evaporation method, had a capacity 


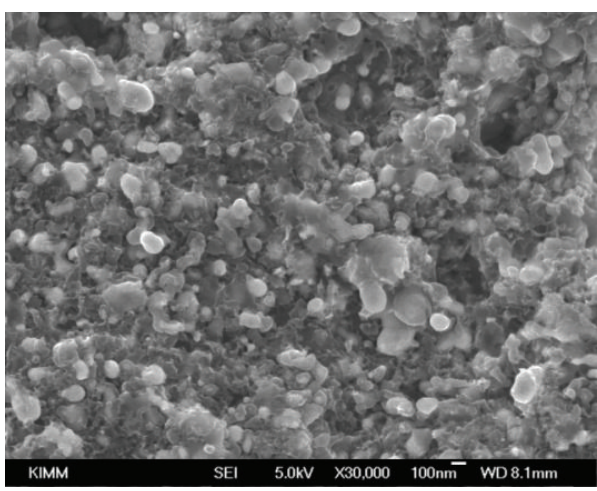

(a)

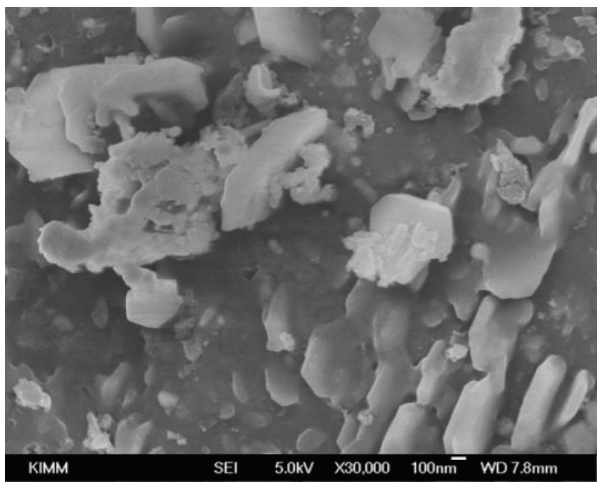

(c)

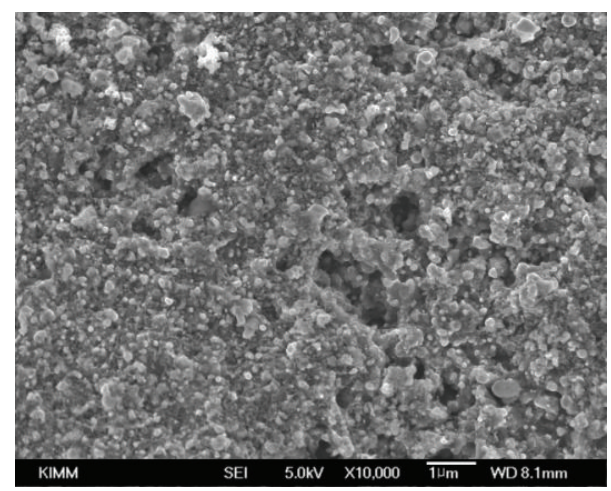

(b)

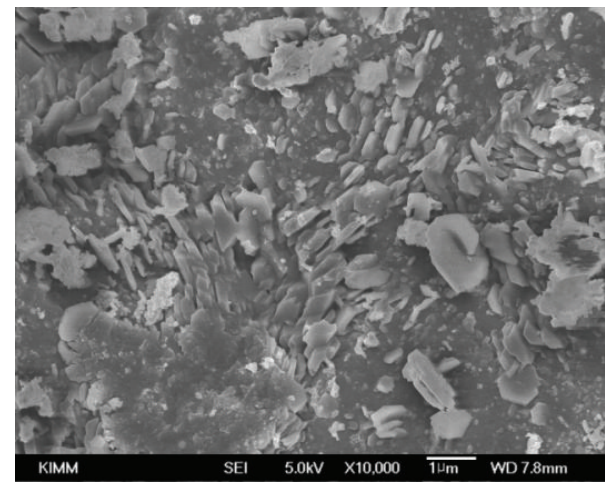

(d)

FIGURE 6: FE-SEM micrographs of the carbon-coated Co-based powders prepared by chemical reduction (a, b) with CTAB and (c, d) without $\mathrm{CTAB}$ and carbon-coating heat treatment at $700^{\circ} \mathrm{C}$ for $1 \mathrm{~h}$.

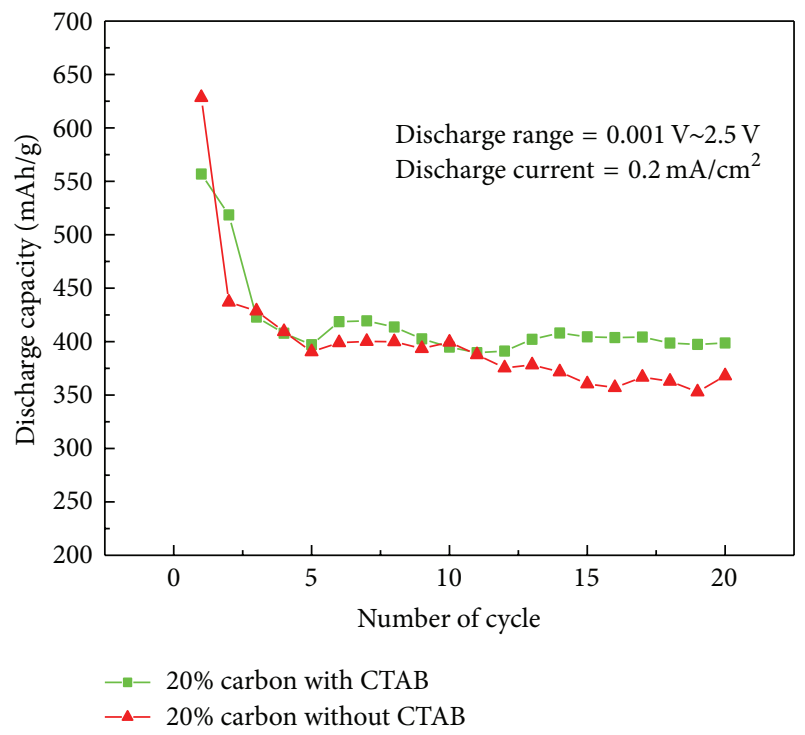

FIGURE 7: Discharge capacity versus cycle number curves of the carbon-coated Co-based electrodes prepared by chemical reduction with and without $\mathrm{CTAB}$ and carbon-coating heat treatment at $700^{\circ} \mathrm{C}$ for $1 \mathrm{~h}$.

of $440 \mathrm{mAh} / \mathrm{g}$ at the first discharge and a reversible capacity of about $280 \mathrm{mAh} / \mathrm{g}$ after 30 cycles. The Li/carbon-coated graphite electrodes were reported by Lee et al. [32] to have a

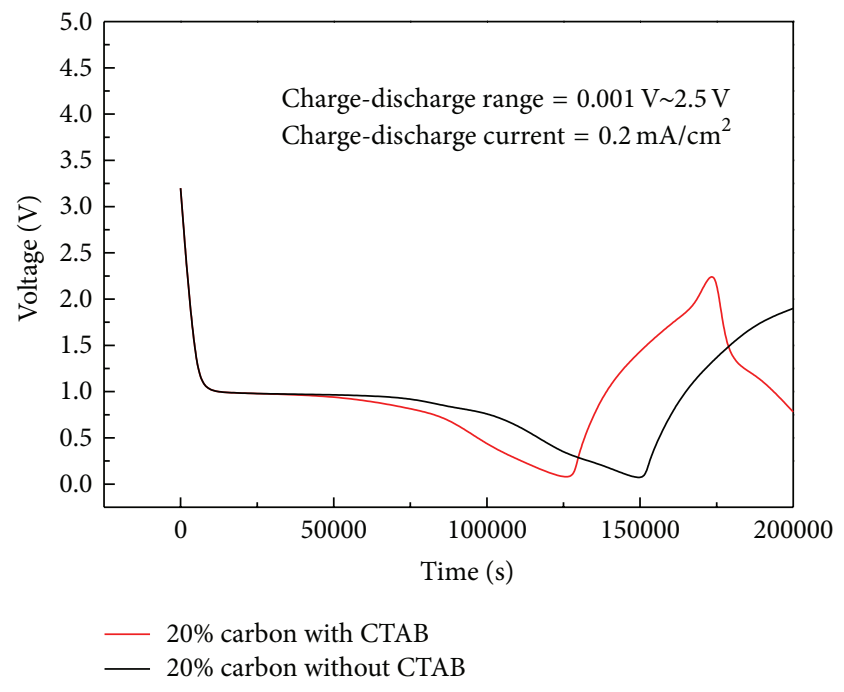

Figure 8: Voltage versus time curves at the first cycle of the carboncoated Co-based electrodes prepared by chemical reduction with and without $\mathrm{CTAB}$ and carbon-coating heat treatment at $700^{\circ} \mathrm{C}$ for $1 \mathrm{~h}$.

reversible capacity of approximately $350 \mathrm{mAh} / \mathrm{g}$. The Li/Cobased cells of this work have smaller discharge capacities than those of nanoparticles of transition-metal oxides [30] and carbon-coated silicon anodes [31] and have the discharge capacities similar to those of the C/Co electrode, 
in which Co nanoparticles are embedded in carbon matrix [21]. However, the Li/Co-based cells of this work have larger discharge capacities than those of the Li/Co cell fabricated with the nanosized Co powder synthesized by a pulsed wire evaporation method [17] and the Li/carbon-coated graphite electrodes [32].

The curves of voltage versus time at the first cycle of the Co-based electrodes prepared by chemical reduction with and without $\mathrm{CTAB}$ and carbon-coating heat treatment at $700^{\circ} \mathrm{C}$ for $1 \mathrm{~h}$ are shown in Figure 8. The two Co-based electrodes have very similar plateau voltages of about $1 \mathrm{~V}$, and the plateau voltage of the Co-based electrode prepared with CTAB and carbon-coated decreases earlier. These plateau voltages are very similar to that $(0.7 \mathrm{~V})$ of the $\mathrm{Li} / \mathrm{Co}$ cell fabricated with the nanosized Co powder prepared via a pulsed wire evaporation method by Kim et al. [17].

\section{Conclusions}

Nanosized amorphous Co-based powders could be synthesized by a chemical reduction method in which a reducing agent is added to Co ions dissolved in an aqueous solution. When the prepared nanosized Co powders were subjected to carbon-coating heating treatment at $700^{\circ} \mathrm{C}$ for $1 \mathrm{~h}$, the amorphous phase was crystallized, and a Co single phase could be obtained. The grain size of the particles prepared by chemical reduction with CTAB and carbon-coating heat treatment was calculated as $33 \mathrm{~nm}$, which was larger than that of $25 \mathrm{~nm}$ obtained for the particles prepared by chemical reduction without CTAB and carbon-coating heat treatment. The Cobased powder prepared with CTAB and carbon-coated had a smaller first discharge capacity (about $557 \mathrm{mAh} / \mathrm{g}$ ) than the Co-based powder prepared without CTAB and carboncoated (about $628 \mathrm{mAh} / \mathrm{g}$ ). However, from the third cycle, the former had a better cycling performance than the latter. Even though the volume expansion was minimized by preparing nanosized particles, quite an abrupt decrease in the discharge capacity observed at the beginning of cycling is believed due to the formation of an SEI, which obstructs the movements of Li ions and electrons. The carbon-coated layers are believed to have led to quite good cycling performances of the prepared Co-based powders from the third cycle.

\section{Conflict of Interests}

The authors declare that there is no conflict of interests regarding the publication of this paper.

\section{Acknowledgment}

This research was performed for the Research Program funded by Korea Institute of Materials Science (KIMS) in South Korea.

\section{References}

[1] L.-L. Xie, X.-Y. Cao, L.-X. Zhang, Z.-X. Dai, and L.-B. Qu, "Synthesis and electrochemical properties of $\mathrm{LiV}_{3} \mathrm{O}_{8} / \mathrm{PAn}$ composite as a cathode material for lithium secondary batteries,"
Electronic Materials Letters, vol. 9, no. 2, pp. 183-186, 2013.

[2] M. S. Yoon, M. Islam, Y. M. Park, and S.-C. Ur, "Effect of synthesizing method on the properties of $\mathrm{LiFePO}_{4} / \mathrm{C}$ composite for rechargeable lithium-ion batteries," Electronic Materials Letters, vol. 9, no. 2, pp. 187-193, 2013.

[3] H. R. Bak, J. H. Lee, B. K. Kim, and W. Y. Yoon, "Electrochemical behavior of $\mathrm{Li} / \mathrm{LiV}_{3} \mathrm{O}_{8}$ secondary cells," Electronic Materials Letters, vol. 9, no. 2, pp. 195-199, 2013.

[4] T. G. Woo, I. S. Park, and K. W. Seol, "The effect of additives and current density on mechanical properties of cathode metal for secondary battery," Electronic Materials Letters, vol. 9, no. 4, pp. 535-539, 2013.

[5] L.-L. Xie, Y.-D. Xu, J.-J. Zhang, C.-P. Zhang, X.-Y. Cao, and L.-B. Qu, "Rheological phase synthesis of Er-doped $\mathrm{LiV}_{3} \mathrm{O}_{8}$ as electroactive material for a cathode of secondary lithium storage," Electronic Materials Letters, vol. 9, no. 4, pp. 549-553, 2013.

[6] Y. K. Kwon, W. C. Choi, H.-S. Choi, and J. K. Lee, "Effect of lithium difluoro (oxalato) borate on $\mathrm{LiMn}_{2} \mathrm{O}_{4}$-activated carbon hybrid capacitors," Electronic Materials Letters, vol. 9, no. 6, pp. 751-754, 2013.

[7] Y. Xu, L. Xie, Y. Zhang, and X. Cao, "Hydrothermal synthesis of hexagonal $\mathrm{MoO}_{3}$ and its reversible electrochemical behavior as a cathode for Li-ion batteries," Electronic Materials Letters, vol. 9, no. 5, pp. 693-696, 2013.

[8] H. J. Kim, B. S. Jin, C. H. Doh, D. S. Bae, and H. S. Kim, "Improved electrochemical performance of doped$\mathrm{LiNi}_{0.5} \mathrm{Mn}_{1.5} \mathrm{O}_{4}$ cathode material for lithium-ion batteries," Electronic Materials Letters, vol. 9, no. 6, pp. 851-854, 2013.

[9] H. J. Kwon, K. Y. Sohn, and W. W. Park, "Electrochemical properties of rapidly solidified $\mathrm{Si}-\mathrm{Ti}-\mathrm{Ni}(-\mathrm{Cu})$ base anode for $\mathrm{Li}-$ ion rechargeable batteries," Electronic Materials Letters, vol. 9, no. 6, pp. 859-863, 2013.

[10] M. M. Atabaki and R. Kovacevic, "Graphene composites as anode materials in lithium-ion batteries," Electronic Materials Letters, vol. 9, no. 2, pp. 133-153, 2013.

[11] Y. Zhao, Y. Huang, Q. Wang et al., "Graphene supported $\mathrm{Li}_{2} \mathrm{SnO}_{3}$ as anode material for lithium-ion batteries," Electronic Materials Letters, vol. 9, no. 5, pp. 683-686, 2013.

[12] K. C. Roh, H. J. Lee, and J. W. Lee, "Nanocomposite of $\mathrm{LiFePO}_{4}$ and mesoporous carbon prepared by microwave heating for rechargeable lithium batteries," Electronic Materials Letters, vol. 9, no. 6, pp. 855-858, 2013.

[13] Y. S. Lee, Y. K. Sun, and K. S. Nahm, "Synthesis and characterization of $\mathrm{LiNiO}_{2}$ cathode material prepared by an adiphic acidassisted sol-gel method for lithium secondary batteries," Solid State Ionics, vol. 118, no. 1-2, pp. 159-168, 1999.

[14] J. Xie, X. B. Zhao, G. S. Cao, Y. D. Zhong, M. J. Zhao, and J. P. Tu, "Solvothermal synthesis of nanosized $\mathrm{CoSb}_{2}$ alloy anode for Liion batteries," Electrochimica Acta, vol. 50, no. 9, pp. 1903-1907, 2005.

[15] S.-H. Hong, J.-S. Bae, and H.-J. Ann, "Synthesis of nano-sized $\mathrm{Co}_{3} \mathrm{O}_{4}$ powder by spray conversion method for anode material of lithium battery," Metals and Materials International, vol. 14, no. 2, pp. 229-232, 2008.

[16] Y. R. Uhm, J. H. Park, W. W. Kim, C.-H. Cho, and C. K. Rhee, "Magnetic properties of nano-size Ni synthesized by the pulsed wire evaporation (PWE) method," Materials Science and Engineering B, vol. 106, no. 3, pp. 224-227, 2004.

[17] D. Y. Kim, H. J. Ahn, J. S. Kim et al., "The electrochemical properties of nano-sized cobalt powder as an anode material for 
lithium batteries," Electronic Materials Letters, vol. 5, no. 4, pp. 183-186, 2009.

[18] J. Chen, L. Yang, S. Fang, and S.-I. Hirano, “Ordered mesoporous $\mathrm{Sn}-\mathrm{C}$ composite as an anode material for lithium ion batteries," Electrochemistry Communications, vol. 13, no. 8, pp. 848-851, 2011.

[19] Y. Liu, C. Mi, L. Su, and X. Zhang, "Hydrothermal synthesis of $\mathrm{Co}_{3} \mathrm{O}_{4}$ microspheres as anode material for lithium-ion batteries," Electrochimica Acta, vol. 53, no. 5, pp. 2507-2513, 2008.

[20] G. F. Ortiz, R. Alcántara, I. Rodríguez, and J. L. Tirado, "New tin-based materials containing cobalt and carbon for lithiumion batteries," Journal of Electroanalytical Chemistry, vol. 605, no. 2, pp. 98-108, 2007.

[21] J. Yue, X. Zhao, and D. Xia, "Electrochemical lithium storage of C/Co composite as an anode material for lithium ion batteries," Electrochemistry Communications, vol. 18, no. 1, pp. 44-47, 2012.

[22] J. Xie, X. Zhao, G. Cao, Y. Zhong, and M. Zhao, "Ex-situ XRD studies of $\mathrm{CoSb}_{3}$ compound as the anode material for lithium ion batteries," Journal of Electroanalytical Chemistry, vol. 542, pp. 1-6, 2003.

[23] Y. Zheng, J. Yang, Y. NuLi, and J. Wang, "Nano-tin alloys dispersed in oxides for lithium storage materials," Journal of Power Sources, vol. 174, no. 2, pp. 624-627, 2007.

[24] J. He, H. Zhao, J. Wang, J. Wang, and J. Chen, "Hydrothermal synthesis and electrochemical properties of nano-sized Co-Sn alloy anodes for lithium ion batteries," Journal of Alloys and Compounds, vol. 508, no. 2, pp. 629-635, 2010.

[25] L. Yiping, G. C. Hadjipanayis, C. M. Sorensen, and K. J. Klabunde, "Magnetic and structural properties of ultrafine CoB particles," Journal of Magnetism and Magnetic Materials, vol. 79, no. 3, pp. 321-326, 1989.

[26] Z.-Z. Yuan, X.-D. Chen, H. Xu, X.-L. Qu, and B.-X. Wang, "Crystallization kinetics of ultrafine $\mathrm{Co}_{74.4} \mathrm{~B}_{25.6}$ amorphous powder prepared by chemical reduction," Journal of Alloys and Compounds, vol. 422, no. 1-2, pp. 109-115, 2006.

[27] J. Lu, D. B. Dreisinger, and W. C. Cooper, "Cobalt precipitation by reduction with sodium borohydride," Hydrometallurgy, vol. 45, no. 3, pp. 305-322, 1997.

[28] J. H. Ahn, "New cell electrode materials using nano-sized powder for lithium secondary battery," Journal of Korean Powder Metallurgy Institute, vol. 9, no. 5, pp. 370-374, 2002.

[29] J. Saida, A. Inoue, and T. Masumoto, "The effect of reaction condition on composition and properties of ultrafine amorphous powders in ( $\mathrm{Fe}, \mathrm{Co}, \mathrm{Ni})$-B systems prepared by chemical reduction," Metallurgical Transactions A, vol. 22, no. 9, pp. 21252132, 1991.

[30] P. Poizot, S. Laruelle, S. Grugeon, L. Dupont, and J.-M. Tarascon, "Nano-sized transition-metal oxides as negative-electrode materials for lithium-ion batteries," Nature, vol. 407, no. 6803, pp. 496-499, 2000.

[31] N. Dimov, S. Kugino, and M. Yoshio, "Carbon-coated silicon as anode material for lithium ion batteries: advantages and limitations," Electrochimica Acta, vol. 48, no. 11, pp. 1579-1587, 2003.

[32] H.-Y. Lee, J.-K. Baek, S.-M. Lee, H.-K. Park, K.-Y. Lee, and M.-H. Kim, "Effect of carbon coating on elevated temperature performance of graphite as lithium-ion battery anode material," Journal of Power Sources, vol. 128, no. 1, pp. 61-66, 2004. 

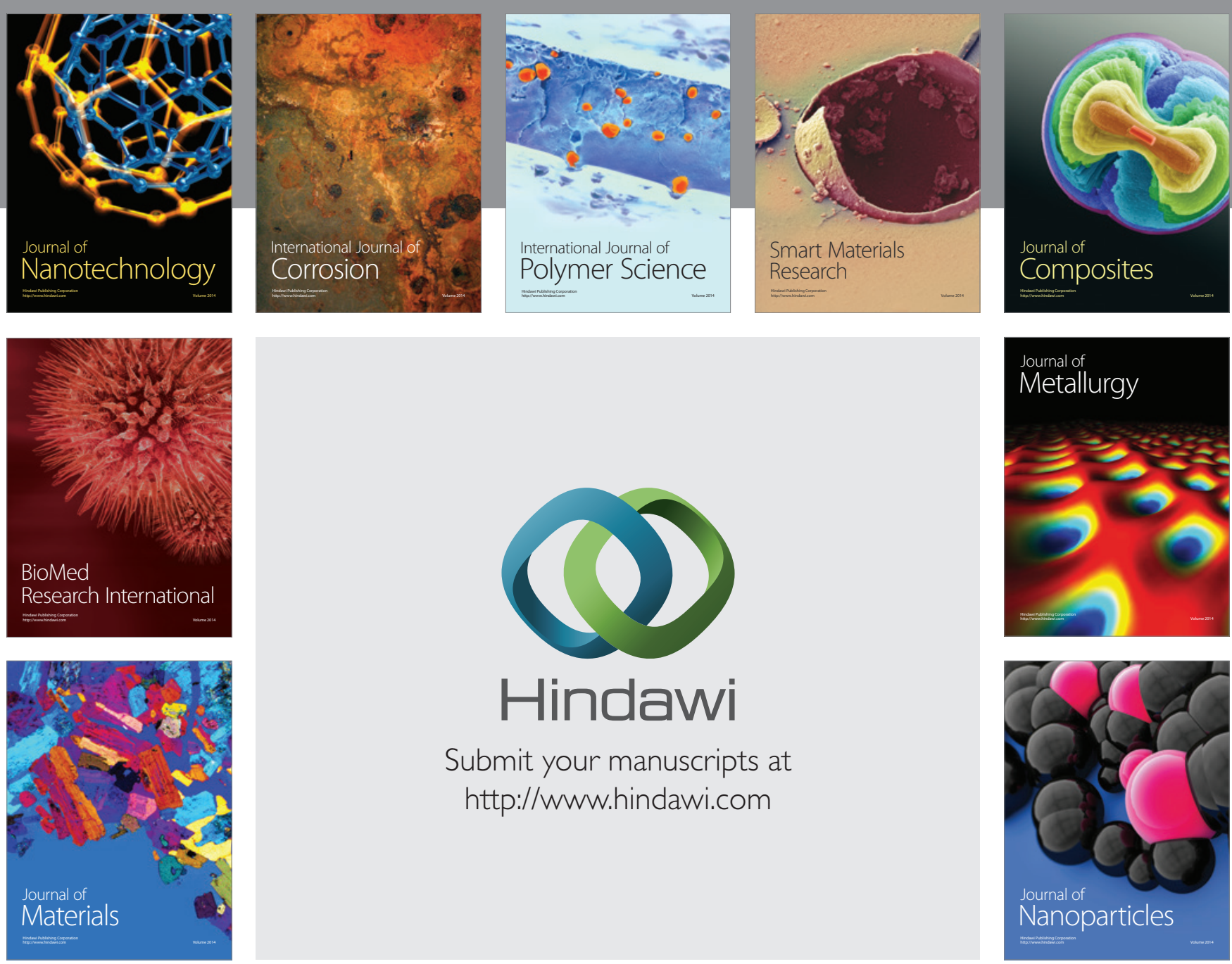

Submit your manuscripts at http://www.hindawi.com
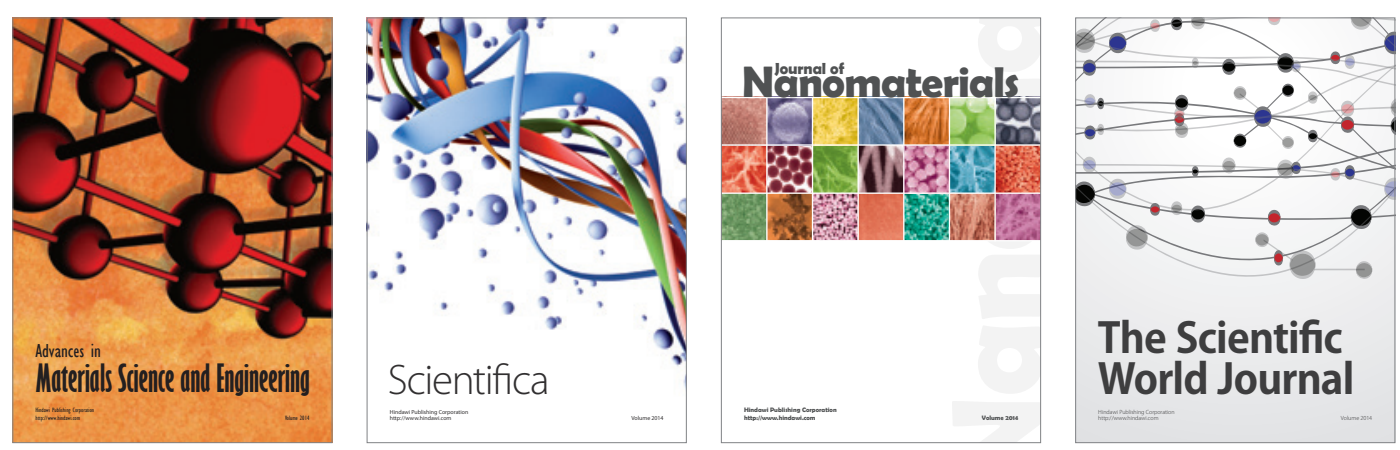

\section{The Scientific World Journal}
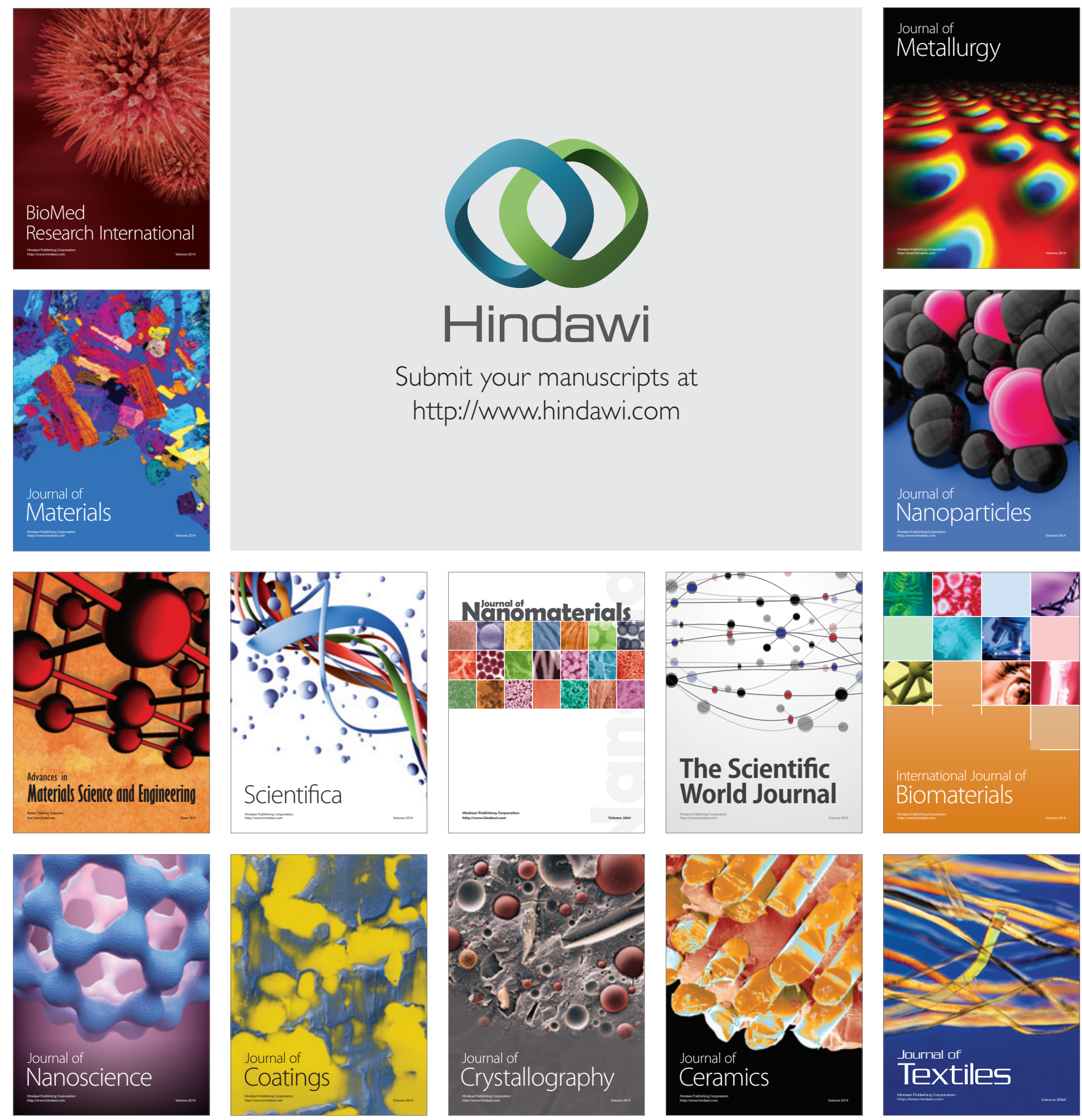